\title{
Additions and corrections
}

\author{
DAVID C. BLACKBURN ${ }^{1} \&$ DAVID B. WAKE ${ }^{2}$ \\ ${ }^{1}$ Department of Vertebrate Zoology \& Anthropology, California Academy of Sciences, San Francisco, CA 94118, USA. \\ E-mail: dblackburn@calacademy.org \\ ${ }^{2}$ Museum of Vertebrate Zoology and Department of Integrative Biology, University of California, Berkeley, CA 94708, USA. \\ E-mail: wakelab@berkeley.edu
}

Recently, we published an invited contribution to Zootaxa in which we summarized the classification of subfamilies, families, and orders of living amphibians (Blackburn \& Wake 2011). Here we contribute minor corrections and additions.

Two higher-level names were spelled inconsistently. The correct spellings are (1) the family Micrixalidae Dubois, Ohler, \& Biju 2001 and (2) the subfamily Plethodontinae Gray 1850. The assignment of several extinct genera was not stated clearly. The salamanders $\dagger$ Batrachosauroides, $\dagger$ Mynbulakia, $\dagger$ Opisthotriton, $\dagger$ Palaeoproteus, $\dagger$ Parrisia, $\dagger$ Peratosauroides, and $\dagger$ Prodesmodon are referred to the $\dagger$ Batrachosauroididae. The frogs $\dagger$ Albionbatrachus, $\dagger$ Messelobatrachus, $\uparrow$ Palaeobatrachus, $\uparrow$ Pliobatrachus were referred to the $†$ Palaeobatrachidae, though we note that the recent revision by Wuttke et al. (2012) leads to three of these genera being synonymized with $\dagger$ Palaeobatrachus (now the single genus in this extinct family). The correct spelling of the taxonomic authority for $\dagger$ Gobiatidae is Roček \& Nessov 1993.

Since our publication, an additional family of caecilians has been described. The Chikilidae Kamei, San Mauro, Gower, Van Bocxlaer, Sherratt, Thomas, Babu, Bossuyt, Wilkinson \& Biju 2012 is currently comprised of the recently erected Chikila. Recently, Gao and Shubin (2012) described the extinct salamander Beiyanerpeton, but it is not assignable to a family of living salamanders.

Below, we include additional cited references and updates to select references then in press.

Last, please note that the title of our paper should be cited as "Class Amphibia Gray, 1825" not "Class Amphibia Gray, 182"; this was an editorial error and the correct citation of our manuscript is listed in the references below.

\section{References}

Augiar, O., Jr., Carvalho, K.A., Giaretta, A.A., \& Recco-Pimentel, S.M. (2004) Cytogenetics of Hylodes and Crossodactylus species (Anura, Leptodactylidae) with comments on Hylodinae/Dendrobatidae relationships. Genetica, 121, 43-53.

Blackburn, D.C., \& Wake, D.B. (2011) Class Amphibia Gray, 1825. In: Zhang, Z.-Q. (Ed.) Animal biodiversity: An outline of higher-level classification and survey of taxonomic richness. Zootaxa, 3148, 39-55.

Brown, R.M., Siler, C.D., Diesmos, A.C., \& Alcala, A.C. (2009) Philippine frogs of the genus Leptobrachium (Anura: Megophryidae): phylogeny-based species delimitation, taxonomic review, and descriptions of three new species. Herpetological Monographs, 23, 1-44.

Brown, J.L., \& Twomey, E. (2009) Complicated histories: three new species of poison frogs of the genus Ameerega (Anura: Dendrobatidae) from north-central Peru. Zootaxa, 2049, 1-38.

Brown, J.L., Twomey, E., Amézquita, A., de Souza, M.B., Caldwell, J.P., Lötters, S., Von May, R., Melo-Sampaio, P.R., MejíaVargas, D., Perez-Peña, P., Pepper, M., Poelman, E.H., Sanchez-Rodriguez, M., \& Summers, K. (2011) A taxonomic revision of the Neotropical poison frog genus Ranitomeya (Amphibia: Dendrobatidae). Zootaxa, 3083, 1-120.

Chippindale, P.T., Bonett, R.M., Baldwin, A.S., \& Wiens, J.J. (2004) Phylogenetic evidence for a major reversal of life-history evolution in plethodontid salamanders. Evolution, 58, 2809-2822.

Delorme, M., Dubois, A., Grosjean, S., \& Ohler, A. (2006) Une nouvelle ergotaxinomie des Megophryidae (Amphibia, Anura). Alytes, 24, 6-21.

Denton, R.K., Jr., \& O'Neill, R.C. (1998) Parrisia neocesariensis, a new batrachosauroidid salamander and other amphibians from the Campanian of eastern North America. Journal of Vertebrate Paleontology, 18, 484-494.

Drewes, R.C. (1984) A phylogenetic analysis of the Hyperoliidae (Anura): treefrogs of Africa, Madagascar, and the Seychelles Islands. Occasional Papers of the California Academy of Sciences, 139, i-x + 1-70.

Edwards, J.L. (1976) Spinal nerves and their bearing on salamander phylogeny. Journal of Morphology, 148, 305-328. 